\title{
Efficacy and Side-Effects of Clozapine: Testing for Association with Allelic Variation in the Dopamine $\mathrm{D}_{4}$ Receptor Gene
}

Marcella Rietschel, M.D., Dieter Naber, M.D., Heinrich Oberländer, M.D., Rüdiger Holzbach, M.D., Rolf Fimmers, Ph.D., Katja Eggermann, B.Sc., Hans-Jürgen Möller, M.D., Peter Propping, M.D., and Markus M. Nöthen, M.D.

Genetic factors are supposed to play a major role not only in the etiology of psychiatric disorders but also in individual response to medications. To test the hypothesis that interindividual differences in response to clozapine and the occurrence of side-effects might be influenced by variations in the dopamine $D_{4}$ receptor gene, we examined frequencies of four known polymorphic sites affecting protein structure in the dopamine $D_{4}$ receptor gene in 149 patients with schizophrenia or schizoaffective disorder treated with clozapine. The $D_{4}$

KEY WORDS: Clozapine; Treatment response; Dopamine $D_{4}$ receptor gene; Pharmacogenetics

The neuroleptic agent clozapine stands out clinically as one of the "atypical" neuroleptics that retain antipsychotic efficacy in spite of being much less likely to cause unwanted extrapyramidal side effects (Meltzer 1995). Although $30 \%$ to $60 \%$ of patients unresponsive to other treatment benefit from clozapine, $40 \%$ to $70 \%$ do not (for review, see Kane 1992). These interindividual differences-also observed with respect to the occurrence of side-effects of clozapine-may be due to the individual genetic make-up of the patient. Compared with the

From the Department of Psychiatry (MR), Institute for Medical Statistics (RF), Institute of Human Genetics (KE, PP, MMN), University of Bonn; Department of Psychiatry (DN, HO, RH, H-JM), University of Munich, Germany.

Address correspondence to: Dr. Marcella Rietschel, Department of Psychiatry, University of Bonn, Sigmund-Freud-Str. 25, D-53127 Bonn, Germany.

Received August 21, 1995; revised February 22, 1996; accepted March 7, 1996. polymorphisms included a 13-base pair deletion, which through a frameshift leads to a truncated nonfunctional receptor protein. There were, however, no significant differences in genotype counts between responders and nonresponders. Furthermore, no side-effect was found to be associated with genetic variants of the dopamine $D_{4}$ receptor. (C) 1996 American College of Neuropsychopharmacology [Neuropsychopharmacology 15:491-496, 1996]

dopamine $\mathrm{D}_{2}$ receptor, clozapine shows an approximately 10-fold higher affinity for the dopamine $\mathrm{D}_{4}$ receptor (Van Tol et al. 1991), suggesting that the $D_{2}$ receptor is the primary target for all neuroleptics, and the dopamine $\mathrm{D}_{4}$ receptor the primary target for clozapine (Seeman et al. 1992).

Interestingly, among the genes for the different dopamine receptors, the gene coding for the dopamine $\mathrm{D}_{4}$ receptor shows an uniquely high degree of genetic variation in the human population, resulting in various structurally different receptor proteins (for review, see Propping and Nöthen 1995). Aside from two amino acid substitutions, there are two repeat and two deletion polymorphisms. The first repeat polymorphism is located in exon 1 of the $\mathrm{D}_{4}$ receptor gene and is characterized by the one to threefold occurrence of a 12-base pair (bp) unit coding for four amino acids in the N-terminal end of the protein (Catalano et al. 1993; own observation). A second repeat polymorphism with a 48-bp repeat unit is located in exon 3 . It is represented in the third cytoplasmatic loop of the receptor protein that 
contains two to 10 repeats of a motif of 16 amino acids (Van Tol et al. 1992). This region is likely to be involved in G-coupling of the protein to its effector systems. In vitro expression studies have shown that the repeat polymorphism influences binding of the atypical antipsychotic clozapine (determined by competition with $\left[{ }^{3} \mathrm{H}\right]$ spiperone binding) (Van Tol et al. 1992; Asghari et al. 1994).

The two deletion variants that were reported for the $D_{4}$ receptor were both found in exon 1 of the $D_{4}$ gene. The more $5^{\prime}$ variant is a 21-bp deletion, which results in a loss of seven amino acids in the first transmembrane domain (Cichon et al. 1995). This is extremely rare, as it was observed only once in more than 500 unrelated individuals. Functional consequences are obvious for the 13-bp deletion, which was also found in exon 1 (Nöthen et al. 1994). This mutation causes a frameshift, which results in a downstream premature stop at codon 99. As such, it probably does not encode a functional protein and therefore is likely to be a null allele (complete loss of function) of the $D_{4}$ receptor. It has an allele frequency of about 0.02 in the general population.

Two amino acid substitutions were reported for the $\mathrm{D}_{4}$ receptor: a substitution of glycine by arginine at position 11 (Gly11Arg) (Cichon et al. 1995) and a substitution of valine by glycine at position 194 (Val194Gly) (Seeman et al. 1994) (the latter variant observed only in individuals of African descent but not in Caucasians and therefore excluded from the present study).

The existence of various genetically determined structurally different dopamine $\mathrm{D}_{4}$ receptor proteins in the human population raises the possibility that individual responsiveness to clozapine and/or the presence of side-effects may be associated with the different $\mathrm{D}_{4}$ alleles an individual carries. Two recent independent studies from the United Kingdom and the United States were unable to find an association between number of the 48-bp repeats and response to clozapine (Shaikh et al. 1993, 1995; Rao et al. 1994). However, as none of the four newly identified $D_{4}$ receptor variants have been investigated so far, the possibility remains that the variable response to clozapine across individuals may be influenced by variability of the $\mathrm{D}_{4}$ receptor gene. To test this hypothesis, we compared genotype counts of the $\mathrm{D}_{4}$ variants in schizophrenic and schizoaffective patients classified with respect to clinical response to clozapine treatment.

\section{METHODS}

\section{Patients}

The medical charts of 868 in-patients treated with clozapine at the Psychiatric Hospital of the University of Munich during 1978 to 1994 were analyzed to evaluate the efficacy and side-effects of clozapine. The efficacy of clozapine treatment was rated as follows: Worsening/ no change (group 0), slight improvement (group 1), marked improvement (group 2), and almost total reduction in symptoms (group 3).

Of the patients, 631 had been given the diagnosis of schizophrenia or schizoaffective disorder; 457 patients could be contacted and these were invited for a personal interview. Of the 255 patients who were willing to cooperate, 231 patients finally were interviewed using the Schedule for Affective Disorders and Schizophrenia-Lifetime Version (SADS-L) (Endicott and Spitzer 1978). Furthermore an OPCRIT 3.3 checklist (McGuffin et al. 1991) was completed for each patient on the basis of a semi-structured diagnostic interview and an examination of the case notes. All patients gave informed consent. Diagnosis was assigned according to DSM-IV criteria (American Psychiatric Association 1994). Patients were not included in molecular analysis unless they were of German descent and met DSM-IV criteria for schizophrenia or schizoaffective disorder. Furthermore, only patients were included who received a minimum of $200 \mathrm{mg}$ (responder groups 0 to 1 ) or $100 \mathrm{mg}$ (responder groups 2 and 3) clozapine daily. We allowed lower daily doses for responder groups 2 and 3, because improvement may also occur at lower doses. Patients had to be treated with clozapine for at least 28 days. As the duration of treatment is crucial and controversially discussed in defining response, we formed two further subgroups excluding patients with shorter duration of treatment than 56 days and 84 days, respectively.

The mean age of the 149 patients (75 males, 74 females) receiving clozapine for more than 28 days and fulfilling the above mentioned criteria was 31.1 years (SD 10.8) at treatment and 35.8 years (SD 10.8) at interview with a mean age of onset of 23.1 years (SD 8.2). Patients were treated for 69.3 days (SD 40.2) with $415.1 \mathrm{mg}$ (SD 202.7) clozapine.

Eighty-four patients were treated for at least 56 days (mean duration 92.7, SD 39.5), 38 patients for at least 84 days (mean duration 121.7, SD 43.2).

One hundred thirty-seven patients had the diagnosis of schizophrenia, and 12 of schizoaffective disorder. One hundred twenty patients were given clozapine because of treatment resistance (defined as having received at least two or more standard neuroleptics for at least 4 weeks before treatment with clozapine) and 29 because they had experienced severe side-effects when treated with standard neuroleptics.

Side-effects of clozapine treatment were ascertained as previously described (Naber et al. 1992). The following side-effects were observed (frequencies are given in brackets): EEG alterations including moderate to profound disturbance of background activity and paroxys- 
mal episodes $(43.6 \%)$, fatigue $(33.6 \%)$, tachycardia $(27.5 \%)$, weight gain $(23.5 \%)$, hypersalivation $(22.1 \%)$, postural hypotension $(17.4 \%)$, increase of liver enzymes (16.1\%), obstipation $(14.1 \%)$, ECG alterations $(10.7 \%)$, leucocytosis $(8.1 \%)$, nausea/vomiting $(7.4 \%)$, fever $(6.7 \%)$, dermatologic signs $(2.7 \%)$, leucopenia $(2.7 \%)$, and delirium $(0.7 \%)$.

\section{Laboratory Procedures}

Leucocyte DNA was isolated as described (Miller et al. 1988).

The four variants located in exon 1 of the dopamine $\mathrm{D}_{4}$ receptor gene were typed simultaneously using a polymerase chain reaction (PCR)-based restriction fragment length polymorphism (RFLP) assay. PCR was performed using primers D4ex1.A (5'-ATGGGGAACCGCAGCACC-3') and D4EX1.B (5'-CTCACCTCGGAGTAGACGAAGAGC-3'). The PCR reaction was carried out in a $25 \mu \mathrm{l}$ volume containing $40 \mathrm{ng}$ genomic template, $10 \mathrm{pmol}$ of each primer, $200 \mu \mathrm{mol} / \mathrm{L}$ of each $\mathrm{dNTP}, 50 \mathrm{mmol} / \mathrm{L} \mathrm{KCl}, 10 \mathrm{mmol} / \mathrm{L}$ Tris- $\mathrm{HCl}$ (pH 8.3), $1.5 \mathrm{mmol} / \mathrm{L} \mathrm{MgCl}, 10 \%$ glycerol, $5 \%$ deionized formamide, and $1 \mathrm{U}$ Taq polymerase (Life Technologies). After an initial denaturation of 5 minutes at $95^{\circ} \mathrm{C}, 35$ cycles of amplification of 30 seconds at $94^{\circ} \mathrm{C}, 30$ seconds at $57^{\circ} \mathrm{C}$, and 30 seconds at $72^{\circ} \mathrm{C}$ and a final extension step of 5 minutes at $72^{\circ} \mathrm{C}$ were performed in a Perkin Elmer 9600 thermocycler. PCR amplification resulted in a fragment of $290 \mathrm{bp}$. An aliquot $(8 \mu \mathrm{l})$ of the PCR product was digested using $3 \mathrm{U} /$ sample of HpaII (Fermentas). At the DNA sequence level the Gly $11 \mathrm{Arg}$ variant is characterized by a $\mathrm{G} \rightarrow \mathrm{C}$ substitution in nucleotide position +31 creating a recognition site for restriction enzyme HpaII. Depending on the absence or presence of the polymorphic HpaII site either a fragment of 53bp (allele Gly11) or two fragments of $31 \mathrm{bp}$ and $22 \mathrm{bp}$ (allele Arg11) are produced. Cleavage in a nonpolymorphic HpaII site results in a constant fragment of $237 \mathrm{bp}$. This fragment was shorter in the presence of a one-fold 12 -bp repeat ( $225 \mathrm{bp})$, the 13 -bp deletion $(224 \mathrm{bp})$, or the 21 -bp deletion (216 bp). The latter variants were distinguishable by different heteroduplex patterns. PCR products from sequenced heterozygotes for the 13-bp deletion, the 21 -bp deletion, and the 12 -bp repeat were used as standards.

The region containing the $48 \mathrm{bp}$ repeat in exon 3 was amplified using primers D4-3 (5'-GCGACTACGTGGTCTACTCG-3') and D4-12 (5'-GGTCTGCGGTGGAGTCTG-3'). PCR conditions were chosen essentially according to the method by Lichter et al. (1993) with the exception that the initial denaturing step was extended to 5 minutes.

PCR fragments were separated in $15 \%$ polyacrylamide gels (acrylamide:bisacrylamide $=49: 1$ ) containing $1 \times \mathrm{TBE}$ and visualized by silver staining (Budowle et al. 1991).

\section{RESULTS}

Genotype counts are shown in Table 1. The 21-bp deletion was not observed in our sample. Data were analyzed by either the $\chi^{2}$ statistic (wherever admissable) or Fisher's exact test (FET) to test the null hypothesis that the distribution of alleles or genotypes between responder groups is no different from chance distribution. No significant differences were noted in the genotype distribution of either the 48-bp repeat $\left(\chi^{2}=11.20\right.$, $d f=9, p=.26$ ), the 12-bp repeat (FET: $p=.46$ ), the 13bp deletion (FET: $p=.94$ ), or the Gly11Arg substitution (FET: $p=.37$ ) among different responder groups. Alleles 2 and 3 (I), alleles 4 and 5 (II), and alleles 6, 7, 8, and 9 (III) of the 48-bp repeat were pooled before $x^{2}$ analysis. Because of small cell counts genotypes I/I and III/III were eliminated from the analysis. No significant differences were observed in pooled allele frequencies of the 48-bp repeat $\left(\chi^{2}=10.17, d f=6, p=.12\right)$.

Because frequencies of the rarer allele of the 12-bp re-

Table 1. Distribution of Dopamine D4 Receptor Genotypes in Clozapine-Treated Patients Relative to Clinical Response

\begin{tabular}{|c|c|c|c|c|c|}
\hline \multirow[b]{2}{*}{ Genotype Counts } & \multicolumn{4}{|c|}{ Responder-Group } & \multirow[b]{2}{*}{ Total } \\
\hline & 0 & 1 & 2 & 3 & \\
\hline \multicolumn{6}{|l|}{ 48-bp Repeat } \\
\hline \multicolumn{6}{|l|}{ Genotype } \\
\hline $2 / 3$ & 0 & 0 & 0 & 1 & 1 \\
\hline $2 / 4$ & 6 & 3 & 6 & 3 & 18 \\
\hline $2 / 7$ & 4 & 1 & 1 & 1 & 7 \\
\hline $3 / 4$ & 1 & 3 & 1 & 2 & 7 \\
\hline $3 / 7$ & 1 & 1 & 0 & 1 & 3 \\
\hline $4 / 4$ & 14 & 14 & 29 & 16 & 73 \\
\hline $4 / 5$ & 0 & 1 & 1 & 0 & 2 \\
\hline $4 / 6$ & 0 & 0 & 1 & 0 & 1 \\
\hline $4 / 7$ & 12 & 7 & 5 & 8 & 32 \\
\hline $4 / 8$ & 1 & 0 & 0 & 0 & 1 \\
\hline $6 / 7$ & 1 & 0 & 0 & 0 & 1 \\
\hline $7 / 7$ & 0 & 1 & 1 & 0 & 2 \\
\hline $7 / 9$ & 0 & 1 & 0 & 0 & 1 \\
\hline \multicolumn{6}{|l|}{ 12-bp Repeat } \\
\hline \multicolumn{6}{|l|}{ Genotype } \\
\hline 1-fold/1-fold & 0 & 1 & 0 & 0 & 1 \\
\hline 1-fold/2-fold & 7 & 7 & 9 & 3 & 26 \\
\hline 2 -fold/2-fold & 33 & 24 & 36 & 29 & 122 \\
\hline \multicolumn{6}{|l|}{ 13-bp Deletion } \\
\hline \multicolumn{6}{|l|}{ Genotype } \\
\hline del/non-del & 1 & 1 & 2 & 2 & 6 \\
\hline non-del/non-del & 39 & 31 & 43 & 30 & 143 \\
\hline \multicolumn{6}{|c|}{ Gly11Arg Substitution } \\
\hline \multicolumn{6}{|l|}{ Genotype } \\
\hline Gly11-Arg11 & 2 & 0 & 0 & 1 & 3 \\
\hline Gly11-Gly11 & 38 & 32 & 45 & 31 & 146 \\
\hline Total & 40 & 32 & 45 & 32 & 149 \\
\hline
\end{tabular}


peat, the 13-bp deletion, and the Gly11Arg polymorphism were low and homozygotes rarely observed, statistical tests of genotypic and allelic association were expected to reveal similar results. We therefore confined the analyses to test for genotypic association.

Subgrouping of patients with respect to duration of treatment resulted in no differences of allele and genotype distributions between responder groups with the exception of allele frequency distribution of the 48-bp repeat in patients receiving clozapine for a minimum duration of 56 days $\left(\chi^{2}=13.1, d f=6, p=.04\right)$. Type III alleles (alleles $6,7,8$, and 9) were more often observed in responder groups 0 and 1 . This result did not remain significant after correction for multiple testing.

The incidence of side-effects is given in the description of the patient sample. To compare distribution of genotypes and alleles between patients with and without specific side-effects, statistical analyses were performed as described for comparison of responder groups. Without correction for multiple testing genotype counts of the 12-bp repeat in patients with nausea differed when compared with patients without nausea (FET: $p=$ .03). However, this difference was of no significance after a correction for multiple testing. Analyses of other side-effects failed to detect statistically significant differences.

The single person homozygous for the one-fold occurrence of the 12-bp repeat showed no specific side-effect, which was not observed in other patients.

In general, allele frequencies found in the patient sample were similar to allele frequencies observed in healthy German persons (Erdmann et al. 1993, Nöthen et al. 1994, Cichon et al. 1995).

\section{DISCUSSION}

Of patients resistant or intolerant to other antipsychotic agents, $30 \%$ to $60 \%$ respond to treatment with clozapine. No phenomenologic, demographic, and/or biologic factors are known that can consistently predict an individual's response or nonresponse to clozapine treatment and/or the occurrence of side-effects. Speculation about the mechanism of action of clozapine has focused on its higher affinity for the dopamine $\mathrm{D}_{4}$ and the serotonin 5-HT receptors relative to other neuroreceptors, thus making these receptors important candidates to account for interindividual differences in clozapine response (Meltzer and Nash 1991; Van Tol et al. 1991). In the present study, we concentrated on a potential influence of the dopamine $\mathrm{D}_{4}$ receptor.

The gene coding for the dopamine $\mathrm{D}_{4}$ receptor shows a uniquely high degree of genetic variation in the human population resulting in various structurally different receptor proteins. The first variants were reported by Van Tol et al. (1992) who observed a twofold to eightfold 48-bp repeat polymorphism in exon 1 resulting in different $D_{4}$ receptors. These receptors manifested a differing affinity for clozapine, raising the possibility that response to clozapine may be attributable to these variants (Van Tol et al. 1992). However, two independent studies from the United Kingdom and the United States were unable to find an association between number of repeats and response to clozapine (Shaikh et al. 1993, 1995; Rao et al. 1994). Also, a more recent study comparing pharmacologic binding profiles of different forms of the repeat variant could only detect small differences in affinity for clozapine between the different polymorphic forms (Asghari et al. 1994). Therefore, it was not too surprising that we failed to detect an effect of the 48-bp repeat in our German sample. However, none of the four newly identified $\mathrm{D}_{4}$ receptor variants have been investigated so far with respect to individual response to clozapine. The variants include a 13-bp deletion, which leads to a truncated nonfunctional receptor protein. In our previous report on the identification of this null mutation, we described a single individual who was homozygous for this mutation (Nöthen et al. 1994). Such an individual provides the unique chance to study the function of the dopamine $D_{4}$ receptor protein by examining a person who completely lacks the functional $\mathrm{D}_{4}$ receptor protein because of his homozygous state. Furthermore, it might be postulated that the clinical effects of the $\mathrm{D}_{4}$ receptor antagonist clozapine to some extent can mimic a loss of dopamine $\mathrm{D}_{4}$ receptor function. The clinical symptomatology of our proband demonstrates some similarity with the side-effects of clozapine, including diverse disturbances of the autonomic nervous system such as weight gain, disturbances of temperature regulation, sweating, and tachycardia (Baldessarini and Frankenburg 1991; Naber et al. 1989, 1992). In the present study, therefore, we not only focused on responsiveness to clozapine but also on the occurrence of side-effects.

However, there were no significant differences in allele frequencies and genotype counts either between responders and nonresponders or between patients in different diagnostic categories. Whereas there was a modest tendency (nonsignificant after correction for multiple testing) of the one-fold occurrence of a 12-bp repeat in exon 1 to be more common in patients with nausea, no other side-effect was found to be associated with genetic variants of the dopamine $\mathrm{D}_{4}$ receptor.

Shaikh et al. (1993) defined response as a 20-point improvement on the Global Assessment Scale (GAS) and Rao et al. (1994) as a 20\% or more decrease in Brief Psychiatric Rating Scale score and a Brief Psychiatric Rating Scale score less than 36 or a Bunney-Hamburg Global Psychosis Rating of less than 6.

We defined four different groups to measure efficacy of treatment. Groups 0 (worsening/no change) and 1 (slight improvement) can be viewed as nonresponders, 
groups 2 (marked improvement) and 3 (an almost total reduction in symptoms) as responders. This should have enable smaller effects to be detected had they stemmed from a special group. We are aware of the problems inherent in investigations based on the analysis of medical records. Nevertheless, in the light of the restrictions attached to the use of clozapine and the personal responsibility of the physicians, patients were carefully observed and clinically relevant data carefully noted.

The time factor is critical in establishing treatment response. Although some patients may continue to improve for many months (Lieberman et al. 1994), significant improvement was observed within the first week of treatment, and this predicted a more favorable treatment response later (Stern et al. 1994). The critical issue remains determining when patients should be classified as nonresponders and what criteria should be used for deciding when to discontinue a treatment trial. Given the risk of agranulocytosis and the associated costs, 4 weeks (mean duration 69.3 days) were considered the minimum in our patients for an adequate trial of antipsychotic medication with clozapine. In this manner, we may have defined some patients as nonresponders who would have eventually improved after a longer course of treatment. On the other hand, medication had to be stopped in those patients with side-effects and little or no improvement on treatment. However, when only patients were included in the analysis who received clozapine for a minimum of 56 days, association data were similarly negative, although there was a tendency of the longer 48-bp repeat alleles to be more often observed in responder groups 0 and 1 (not significant after correction for multiple testing). In summary: if a substantial difference between responders and nonresponders existed, it should have been detected, although smaller effects might have been missed. It is also possible that existing effects may have been masked on account of the heterogeneity of the patient group. However, when the analysis was restricted to patients with the diagnosis of schizophrenia $(n=137)$ or to those who had been treatment resistant to other neuroleptics $(n=120)$, similar negative results were obtained.

Although the analyzed side-effects may also appear under treatment with other neuroleptics, clozapine has a side-effect profile that is in many ways distinct from standard typical antipsychotic drugs. The most common side-effects include hypersalivation, orthostasis, EEG alteration, and weight gain, which theoretically could be attributable to the different $\mathrm{D}_{4}$ alleles. Taking into account the limited sample sizes of patients with specific side-effects, it is possible that an association of a mutation contributing only a small effect (perhaps in conjunction with other-as yet undefined-factors) may have been missed.

Finally, there remains the possibility that variation in regulatory sequences of the $D_{4}$ receptor gene might influence treatment response. This view seems to be supported by the observation of Kennedy and co-workers (1994) who found a high predictive power when the 48-bp repeat was combined with polymorphisms in noncoding areas, which they explained by the existence of functionally relevant variation in regulatory sequences in linkage disequilibrium with the investigated markers. At the moment, however, no further data exist to support this hypothesis. The regulatory sequences of the $D_{4}$ gene have yet to be defined at the molecular level.

We may have also missed an existing association of the 48-bp polymorphism, because we had only tested for association with the number of the repeats. Further DNA sequence analysis of the repeat region indicated that the alleles vary not only in the number of repeat units but also in the sequence of the repeats and the order in which they appear (Lichter et al. 1993). Sequencing of 178 subjects identified 19 different repeats in 25 different haplotypes coding for 18 different amino acid sequencies. This second dimension of variation may have additional consequences on the binding characteristics of receptor variants.

In summary, our findings do not support the hypothesis that the hitherto known coding mutations in the dopamine $D_{4}$ receptor gene account for the differences in response to clozapine. The hope some have held for an easy and rapid test to inform patients in advance about the possible outcome of treatment and any associated specific side-effects still remains unfulfilled.

\section{ACKNOWLEDGMENTS}

We thank Prof. K. Koehler for critical reading of the manuscript. The work was supported by grants from the Deutsche Forschungsgemeinschaft (P.P., M.N., R.F.) and a grant from the Herbert-Reeck-Stifung (M.N., M.R.).

\section{REFERENCES}

American Psychiatric Association (1994): Diagnostic and Statistical Manual of Mental Disorders. 4th ed. Washington, DC, American Psychiatric Association

Asghari V, Schoots O, Van Kats S, Koichi O, Jovanovic V, Guan H-G, Bunzow JR, Petronis A, Van Tol HHM (1994): Dopamine D4 receptor repeat: Analysis of different native and mutant forms of the human and rat genes. Mol Pharmacol 46:364-373

Baldessarini RJ, Frankenburg FR (1991): Clozapine. A novel antipsychotic agent. N Engl J Med 324:746-754

Budowle B, Chakraborty R, Giusti AM, Eisenberg AJ, Allen RC (1991): Analysis of the VNTR locus D1S80 by the PCR followed by high-resolution PAGE. Am J Hum Genet 48:137-144 
Catalano M, Nobile M, Novelli E, Nöthen MM, Smeraldi E (1993): Distribution of a novel mutation in the first exon of the human dopamine $D_{4}$ receptor gene in psychotic patients. Biol Psychiatry 34:459-464

Cichon S, Nöthen MM, Catalano M, Di Bella D, Maier W, Lichtermann D, Minges J, Albus M, Borrmann M, Franzek E, Stöber G, Weigelt B, Körner J, Rietschel M, Propping P (1995): Identification of two novel polymorphisms and a rare deletion variant in the human dopamine $D_{4}$ receptor gene. Psychiatr Genet 5:97-103

Endicott J, Spitzer RL (1978) A diagnostic interview: The schedule for affective disorders and schizophrenia. Arch Gen Psychiatry 35:837-844

Erdmann J, Nöthen MM, Cichon S, Körner J, Rietschel M, Lanczik M, Catalano M, Propping P (1993): Association study of a coding polymorphism in exon 1 of the dopamine D4 receptor gene and major psychoses. Psychiatr Genet 3:164 (abstract)

Kane JM (1992): Clinical efficacy of clozapine in treatmentrefractory schizophrenia: An overview. Br J Psychiatry 160(Suppl 17):41-45

Kennedy JL, Petronis A, Macciardi FM, Van Tol HHM, Cola P, Meltzer HY (1994): The D4 dopamine receptor gene, clozapine response, and schizophrenia. Neuropsychopharmacology 10:897S (abstract)

Lieberman JA, Safferman AZ, Pollack S, Szymanski S, Johns C, Howard A, Kronig M, Bookstein P, Kane J (1994): Clinical effects of clozapine in chronic schizophrenia: Response to treatment and predictors of outcome. Am J Psychiatry 151:1744-1752

Lichter JB, Barr CL, Kennedy JL, Van Tol HHM, Kidd KK, Livak KJ (1993): A hypervariable segment in the human dopamine receptor $\mathrm{D}_{4}$ (DRD4) gene. Hum Mol Genet 2:767-773

McGuffin P, Farmer A, Harvey I (1991): A polydiagnostic application of operational criteria in studies of psychotic illness. Arch Gen Psychiatry 48:764-770

Meltzer HY, Nash JF (1991): VII. Effects of antipsychotic drugs on serotonin receptors. Pharmacol Rev 43:587604

Meltzer HY (1995): Clozapine: Is another view valid? Am J Psychiatry 152:821-825

Miller SA, Dykes DD, Polesky HF (1988): A simple salting out procedure for extracting DNA from human nucleated cells. Nucleic Acids Res 16:1215

Naber D, Leppig M, Grohmann R, Hippius H (1989): Efficacy and adverse effects of clozapine in the treatment of schizophrenia and tardive dyskinesia-A retrospective study of 387 patients, Psychopharmacology 99 (Suppl): $73-76$

Naber D, Holzbach R, Perro C, Hippius H (1992): Clinical management of clozapine patients in relation to efficacy and side-effects. Br J Psychiatry 160:54-59

Nöthen MM, Cichon S, Hemmer S, Hebebrand J, Remschmidt H, Lehmkuhl G, Poustka F, Schmidt M, Catalano M, Fimmers R, Körner J, Rietschel M, Propping P (1994): Human dopamine D4 receptor gene: Frequent occurrence of a null allele and observation of homozygosity. Hum Mol Genet 3:2207-2212.

Propping P, Nöthen MM (1995): Genetic variation of CNS receptors-A new perspective for pharmacogenetics. Pharmacogenetics 5:318-325

Rao PA, Pickar D, Gejman PV, Ram A, Gershon ES, Gelernter J (1994): Allelic variation in the D4 dopamine receptor (DRD4) gene does not predict response to clozapine. Arch Gen Psychiatry 51:912-917

Seeman P (1992): Dopamine receptor sequences. Therapeutic levels of neuroleptics occupy $\mathrm{D}_{2}$ receptors, clozapine occupies D4. Neuropsychopharmacology 7:261-284

Seeman P, Ulpian C, Chouinard G, Van Tol HHM, Dwosh H, Lieberman JA, Siminovitch K, Liu IS, Waye J, Voruganti P, Hudson C, Serjeant GR, Masibay AS, Seeman MV (1994): Dopamine D4 receptor variant, D4GLYCINE194, in Africans, but not in Caucasians: No association with schizophrenia. Am J Med Genet 54:384-390

Shaikh S, Collier DA, Kerwin RW, Pilowsky LS, Gill M, Zu WM, Thorton A (1993): Dopamine D4 receptor subtypes and response to clozapine. Lancet 341:116

Shaikh S, Collie DA, Sham P, Pilowsky L, Sharma T, Lin LK, Crocq MA, Gill M, Kerwin R (1995): Analysis of clozapine response and polymorphisms of the dopamine D4 receptor gene (DRD4) in schizophrenic patients. Am J Med Genet 60:541-545

Stern RG, Kahn RS, Davidson M, Nora RM, Davis KL (1994): Early response to clozapine in schizophrenia. Am J Psychiatry 151:1817-1818

Van Tol HHM, Bunzow JR, Guan H-C, Sunahara RK, Seeman P, Niznik HB, Civelli O (1991): Cloning of the gene for a human dopamine $D_{4}$ receptor with high affinity for the antipsychotic clozapine. Nature 350:610-614

Van Tol HHM, Wu CM, Guan H-C, Ohara K, Bunzow JR, Civelli O, Kennedy J, Seeman P, Niznik HB, Jovanovic V (1992): Multiple dopamine $\mathrm{D}_{4}$ receptor variants in the human population. Nature 358:149-152 